\title{
Narcolepsy in Parkinson's disease with insulin resistance
}

\section{[version 1; peer review: 3 approved with reservations]}

\author{
Alisha Chunduri (D1,2, Wim E. Crusio (iD) 3,4, Anna Delprato (iD) 2,3 \\ 1Department of Biotechnology, Chaitanya Bharathi Institute of Technology, Hyderabad, 500075, India \\ ${ }^{2}$ Department of Research and Education, BioScience Project, Wakefield, MA, 01880, USA \\ ${ }^{3}$ Institut de Neurosciences Cognitives et Intégratives d'Aquitaine, CNRS UMR 5287, Pessac, 33615, France \\ ${ }^{4}$ Institut de Neurosciences Cognitives et Intégratives d'Aquitaine, UMR 5287 University of Bordeaux, Pessac, 33615, France
}

\begin{tabular}{l}
\hline F1 \\
https://doi.org/10.12688/f1000research.27413.1 \\
Second version: 20 Oct 2021, 9:1361 \\
https://doi.org/10.12688/f1000research.27413.2 \\
Latest published: 20 Jan 2022, 9:1361 \\
https://doi.org/10.12688/f1000research.27413.3 \\
\hline
\end{tabular}

\section{Abstract}

Background: Parkinson's disease (PD) is characterized by its progression of motor-related symptoms such as tremors, rigidity, slowness of movement, and difficulty with walking and balance. Comorbid conditions in PD individuals include insulin resistance (IR) and narcolepsy-like sleep patterns. The intersecting sleep symptoms of both conditions include excessive daytime sleepiness, hallucinations, insomnia, and falling into REM sleep more quickly than an average person. Understanding of the biological basis and relationship of these comorbid disorders with PD may help with early detection and intervention strategies to improve quality of life.

Methods: In this study, an integrative genomics and systems biology approach was used to analyze gene expression patterns associated with PD, IR, and narcolepsy in order to identify genes and pathways that may shed light on how these disorders are interrelated. A correlation analysis with known genes associated with these disorders ( $L R R K 2, H L A-D Q B 1$, and HCRT) was used to query microarray data corresponding to brain regions known to be involved in PD and narcolepsy. This includes the hypothalamus, dorsal thalamus, pons, and subcoeruleus nucleus. Risk factor genes for PD, IR, and narcolepsy were also incorporated into the analysis.

Results: The PD and narcolepsy signaling networks are connected through insulin and immune system pathways. Important genes and pathways that link PD, narcolepsy, and IR are CACNA1C, CAMK1D, BHLHE41, HMGB1, and AGE-RAGE.

Conclusions: We have identified the genetic signatures that link PD with its comorbid disorders, narcolepsy and insulin resistance, from the convergence and intersection of dopaminergic, insulin, and immune system related signaling pathways. These findings may aid in the design of early intervention strategies and treatment regimes for non-motor symptoms in PD patients as well as individuals with

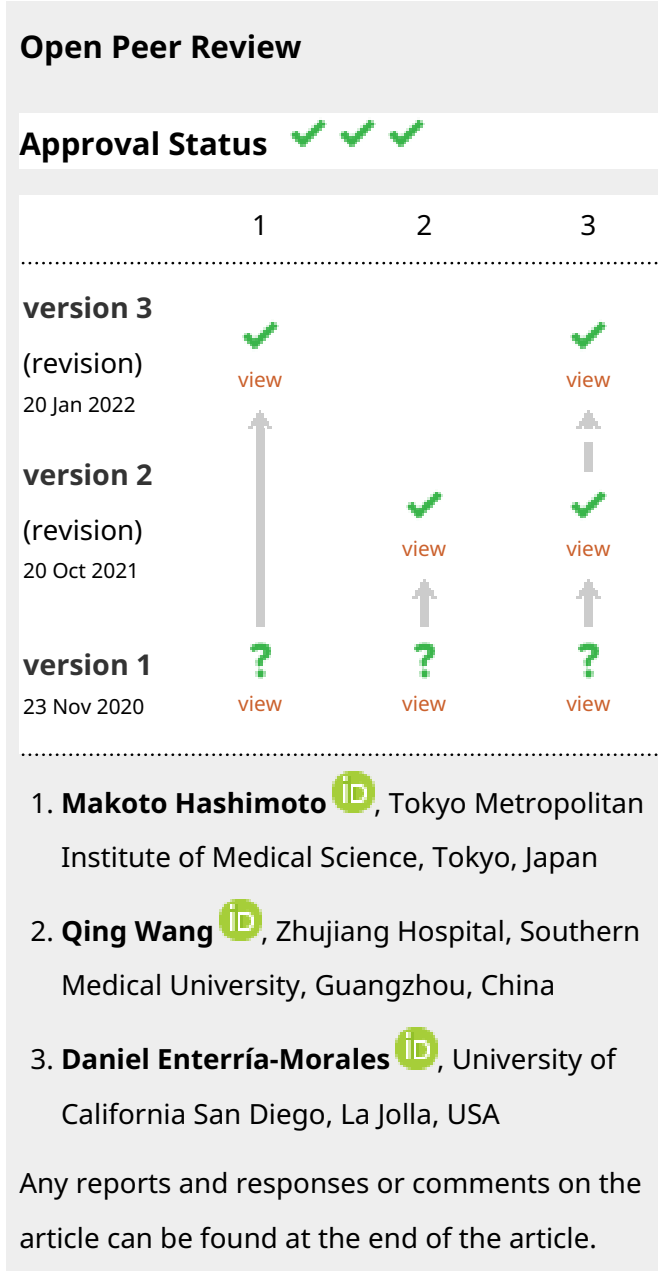


diabetes and narcolepsy.

Keywords

Parkinson's disease, narcolepsy, insulin resistance, diabetes, circadian

This article is included in the Circadian Clocks in

Health and Disease collection.

Corresponding author: Anna Delprato (adelprato@bioscienceproject.org)

Author roles: Chunduri A: Conceptualization, Data Curation, Formal Analysis, Funding Acquisition, Investigation, Methodology, Resources, Validation, Visualization, Writing - Original Draft Preparation, Writing - Review \& Editing; Crusio WE: Formal Analysis, Funding Acquisition, Investigation, Methodology, Writing - Original Draft Preparation, Writing - Review \& Editing; Delprato A: Conceptualization, Data Curation, Formal Analysis, Funding Acquisition, Investigation, Methodology, Resources, Supervision, Validation, Visualization, Writing - Original Draft Preparation, Writing - Review \& Editing

Competing interests: No competing interests were disclosed.

Grant information: The author(s) declared that no grants were involved in supporting this work.

Copyright: @ 2020 Chunduri A et al. This is an open access article distributed under the terms of the Creative Commons Attribution License, which permits unrestricted use, distribution, and reproduction in any medium, provided the original work is properly cited.

How to cite this article: Chunduri A, Crusio WE and Delprato A. Narcolepsy in Parkinson's disease with insulin resistance [version 1; peer review: 3 approved with reservations] F1000Research 2020, 9:1361 https://doi.org/10.12688/f1000research.27413.1

First published: 23 Nov 2020, 9:1361 https://doi.org/10.12688/f1000research.27413.1 


\section{Introduction}

Parkinson's disease (PD) is characterized by its progression of motor-related symptoms such as tremors, rigidity, slowness of movement, and difficulty with walking and balance ${ }^{1}$. The motor difficulties associated with PD are attributed to the loss of dopaminergic neurons in the substantia nigra ${ }^{1}$. There are also non-dopamine lesions that are involved in PD that include the caudal group of intralaminar nuclei (located in dorsal thalamus), and subcoeruleus nuclei ${ }^{1}$. The main genetic cause of $\mathrm{PD}$ is attributed to mutation of the LRRK2 (leucine-rich repeat kinase 2) gene ${ }^{2,3}$.

Sleep disruption is another manifestation of LRRK2-PD and is often more disturbing than the motor symptoms ${ }^{4}$. Most PD patients have daytime sleep attacks and REM sleep disorder that resemble narcolepsy associated sleep symptoms such as excessive daytime drowsiness, sleep paralysis, hallucinations ${ }^{5}$, and in some cases episodes of cataplexy ${ }^{6}$. People with narcolepsy frequently enter REM sleep rapidly, within 15 minutes of falling asleep and the muscle weakness or dream activity of REM sleep can occur during wakefulness or be absent during sleep ${ }^{7}$. Alleles of the HLA-DQB1 (major histocompatibility complex, class II, DQ beta 1) gene are associated with a predisposition to narcolepsy ${ }^{8}, \mathrm{PD}^{9}$, and Type I diabetes ${ }^{10}$. There is also a significantly increased risk of PD among patients with a history of diabetes ${ }^{11}$.

Besides $H L A-D Q B 1$, the relationship between PD, narcolepsy, and IR may be in part attributed to the hypocretins/orexins which are produced by the HCRT gene ${ }^{12}$. Hypocretins are neurotransmitters that are manufactured by a small number of neurons in the hypothalamus ${ }^{13}$. They act to stimulate target neurons and promote wakefulness while suppressing rapid-eyemovement (REM) sleep ${ }^{14}$. Research has shown that there is a massive loss of hypocretin neurons in patients of both PD and narcolepsy and it is hypothesized that the reduction of hypocretin may be the underlying pathogenesis of the narcoleptic symptoms in $\mathrm{PD}^{5,15,16}$. In addition to their role in narcolepsy and PD, hypocretins modulate glucose and insulin metabolism ${ }^{15}$. In this study we explore the connection between PD, narcolepsy, and IR using an integrative genomics and systems biology approach.

\section{Methods}

\section{Genesets and evaluation}

Microarray data was collected from the Allen Brain Database using the Human Brain Atlas. To obtain the data, a gene search for $L R R K 2$, $H L A-D Q B 1$, and $H C R T$ was performed. Each of these genes were used to query the atlas for correlates to the hypothalamus, dorsal thalamus, pons, and subcoeruleus nucleus using the dropdown menu for each of the six donor post-mortem brains available in the Allen Human Brain Atlas.

Genes whose expression pattern correlated with LRRK2, $H L A-D Q B 1$, and $H C R T$ were collected for analysis. Correlates with a range of Pearson $\mathrm{r}$ values from 0.6 to 1.0 were considered in the analysis (Extended data, Workbook $1^{17}$ ). The rationale was to investigate genes with a similar expression pattern in order to identify gene correlates specific and common to LRRK2, HLA-DQB1, and HCRT. Risk factor genes and genes contributing to $\mathrm{PD}$, narcolepsy, and IR were obtained from OMIM, Harmonizome, and GeneWeaver.

Each geneset was evaluated using Gene Ontology (GO) enrichment for clustering, pathways, and keywords using the Database for Annotation, Visualization and Integrated Discovery (DAVID, version 6.8) and the Gene Ontology databases with integrated tools for analysis. Clustering was done in DAVID using the default parameters which include medium stringency settings and a kappa similarity value of 3 . The Benjamini corrected P-value was used to determine enrichment significance. The pathway enrichment was performed using KEGG and Panther pathways. The pathways were analyzed manually and evaluated based on shared themes. For the keyword enrichment, a keyword search of the DAVID functional annotation table output was used to identify genes associated with relevant traits related to $L R R K 2$, $H L A-D Q B 1$, and $H C R T$ function. The keywords considered were 'sleep', 'circadian', 'parkinson', 'locomotion', 'dopamine', 'behavior', 'learning', 'memory', and 'transcription factor'. Geneset overlap was assessed using Venny 2.0, an online program that compares lists of items to determine the common and unique genes between $L R R K 2$, $H L A-D Q B 1$, and $H C R T$ within and among each brain region (hypothalamus, dorsal thalamus, pons, and subcoeruleus nucleus). Geneset overlap was visualized with the UpSet Library in RStudio, $\mathrm{R}$ Version 4.0.2.

\section{Network analysis}

The String database (version 11.0) was used to build a protein-protein interaction network (PPI) for LRRK2, HLA-DQB1, HCRT and CAMK1D which was identified in this study as the only common risk factor gene associated with PD, narcolepsy and IR (Results section: "Functional analysis of PD, narcolepsy and IR risk factor and related genes"). The network was constructed based on experimentally validated interactions using the medium confidence score of 0.4. The combined scores for the interactions are computed by combining the probabilities from the different evidence channels and corrected for the probability of randomly observing an interaction. First and 2nd shell interactions are included in the network. The network was exported from STRING and analyzed in Cytoscape (version 3.7). Network bottlenecks and clusters were identified with Cytoscape plugins CytoHubba (version 0.1 ) and MCODE (version 1.6.1), respectively. ClueGo (version 2.5.7) was used to analyze the common risk factors and contributing genes for PD, narcolepsy, and IR. The nodes in the network have been manually arranged for proper visibility. Select enriched terms are included in the network (Figure 3A). All of the enriched terms are provided in Extended data, Workbook 5 , sheet $5^{18}$.

\section{Results}

\section{Functional analysis of gene correlates}

The cluster analysis for the LRRK2, HLA-DQB1, and HCRT gene correlates for each brain region resulted in significant enrichment categories for only $H L A-D Q B 1$ related genesets. For LRRK2 and HCRT there are several instances in which clusters contained enrichment terms for insulin, diabetes, PD, other neurodegenerative disorders, and circadian processes but these did not achieve significance based on the corrected $\mathrm{P}$ value 
criteria. Also, of note for almost every set of correlates, there were many significant enrichment categories and corresponding genes associated with keratinocytes/keratin and olfaction. The clustering results for each set of gene correlates are listed in Extended data, Workbook $2^{19}$.

For the HLA-DQB1 clusters, the significant enrichment terms are: dorsal thalamus: hsa05012:Parkinson's disease ( $\mathrm{P}=4.38 \mathrm{E}-06)$, 31 genes and hsa04940:Type I diabetes mellitus ( $\mathrm{P}=0.03)$, 10 genes; subcoeruleus nucleus: hsa04940:Type I diabetes mellitus ( $\mathrm{P}=6.13 \mathrm{E}-05), 15$ genes, and pons: hsa04940:Type I diabetes mellitus, six genes $(\mathrm{P}=0.001)$. The other genes and enrichment categories clustering with $\mathrm{PD}$ in the dorsal thalamus are related to mitochondria processes such as oxidative phosphorylation and electron transport as well as Alzheimer's disease (AD) and Huntington disease (HD).

\section{Geneset overlap}

Among the sets of gene correlates for LRRK2, HLA-DQB1 and $H C R T$, there are 10 common genes in both the dorsal thalamus and subcoeruleus nucleus (HNRNPU, GDF11, ROCK1, GABRA4, PFKFB2, ZNF846, PAK2, A_32_P232747, SLC9A3R2, and DISC1; Figure 1B). Among the relevant genes are ROCK1, which is involved in negative regulation of neuron apoptotic processes, DISC1 associated with neuron migration, and HNRNPU involved in circadian regulation of gene expression. The ten common genes in the subcoeruleus nucleus are LAMP2, LOC653110,
HNRNPU, SLC6A6, PHTF2, ITGB2, OPA3, GLYAT, HCN4, and $H M G B 1$, among which the relevant ones to this study are $H N R N P U$, which as mentioned above is involved in circadian regulation of gene expression and insulin signaling, ITGB2, which is associated with PD and IR, and $H M G B 1$, which is a ligand for the RAGE receptor. Among the sets of gene correlates for $L R R K 2, H L A-D Q B 1$, and $H C R T$, there are no common correlated genes in the hypothalamus and pons.

A detailed description of all shared genes and their associated function for each brain region is provided in Extended data, Workbook 3 (sheets $1-8)^{20}$. Briefly, the dorsal thalamus and subcoeruleus nucleus have the largest number of shared correlates between $L R R K 2, H C R T$, and HLA-DQB1. Many of these genes for both brain regions are associated with neuron, insulin, and dopamine related processes. There are also several genes connected directly to PD. In sharp contrast, however, the dorsal thalamus associated correlates have many genes linked to circadian function

In the dorsal thalamus, the relevant genes are associated with neuron function (negative regulation of neuron apoptotic process, neuron projection development and regulation, neuron differentiation, neuron fate commitment, neuron death in response to oxidative stress, neuron regeneration), circadian processes (regulation of circadian rhythm, circadian entrainment, circadian regulation of gene expression, regulation of circadian rhythm,

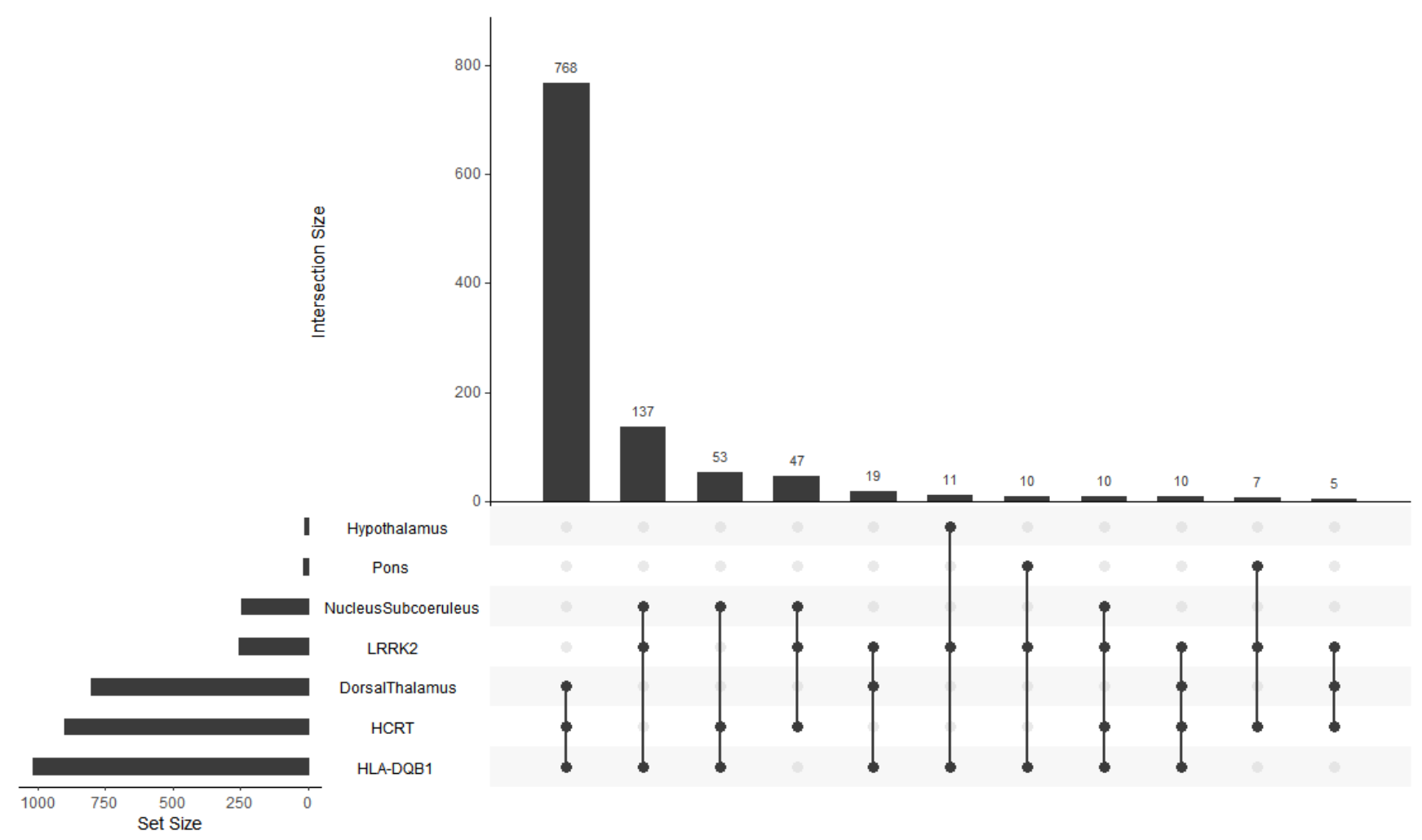

Figure 1. Geneset overlap. Shared correlates for LRRK2, HLA-DQB1 and HCRT over all brain regions. X-axis, Intersection size; Y-axis, Gene number and brain regions. 
entrainment of circadian clock by photoperiod), and insulin signaling (insulin secretion, insulin receptor signaling, insulin secretion). Other genes of interest are related to dopamine (dopaminergic neuron differentiation, regulation of dopamine uptake involved in synaptic transmission, positive regulation of dopamine secretion, Wnt signaling pathway involved in midbrain dopaminergic neuron differentiation, dopamine receptor binding, dopamine biosynthetic process, adenylate cyclase-activating dopamine receptor signaling pathway) and also behavior (locomotory, feeding, learning, memory and vocalization, response to stimulants).

In the subcoeruleus nucleus, the relevant genes are also associated with neuron function (negative regulation of neuron differentiation, dopaminergic neuron differentiation, neuron apoptotic process, negative regulation of neuron differentiation, forebrain neuron differentiation), insulin signaling (insulin secretion, insulin receptor signaling pathway, negative regulation of insulin receptor signaling pathway, positive regulation of insulin secretion, diabetes mellitus), dopamine related processes (dopaminergic synapse, dopamine biosynthetic process, dopaminergic neuron differentiation, regulation of synaptic transmission, dopaminergic dopamine biosynthetic process from tyrosine), and behavior (locomotory, vocal learning, response to fear, grooming, response to stimulants).

There are few shared correlated genes in the hypothalamus and pons. For the hypothalamus, the most pertinent genes are involved in neuron migration and circadian processes. In the pons, the relevant genes are concerned with negative regulation of neuron apoptotic processes, neuron projection, circadian regulation of gene expression, and hippocampus and pyramidal neuron development.

Geneset overlap of the correlates for LRRK2, HLA-DQB1, and $H C R T$ was assessed within each brain region (see Extended data, Workbook 3, sheets $\left.9-11^{20}\right)$. Of the LRRK2 correlates, $1.6 \%$ were common in all 4 brain regions. Among these are genes associated with insulin (MAX, NUCKS1, PIK3R1, PTPN11), diabetes $(P I K 3 R 1)$ and circadian-related processes (HNRNPU, $B H L H E 41)$. Several transcription factors were also present (MAX, SKI, ATF7IP, NUCKS1, BHLHE41, NR2C2, PIK3R1). One of these, BHLHE41, acts as a negative regulator of orexin, controls circadian rhythms, and is associated with short sleep syndrome and advanced sleep phase disorder. For HLA-DQB1, 1.2\% of the correlates are common in all brain regions; relevant associated themes include PD and dopamine (SLC18A1) insulin (HLA-DRB5, HLA-DOA, HLA-DQA1, HLA-DQB1) and transcription factors (PYCARD, SOX8, FOXE3, LGALS9, HMGB1, ZNF446). Only $0.2 \%$ of the HCRT correlates are common among all brain regions considered. This includes $H C R T$ itself and an insulin associated gene, GHSR. Of note, the $M O G$ gene, which is present among the $H L A-D Q B 1$ correlates of the subcoeruleus nucleus and $H C R T$ correlates of the hypothalamus, is a risk factor for narcolepsy and is linked to PD.

\section{Keyword evaluation of gene correlates}

From the GO analysis of the gene correlates, a functional annotation table was generated for GO Biological Process. Genes associated with keywords were obtained and their frequencies determined. The keyword categories used are as follows: sleep, circadian, Parkinson, locomotion, dopamine, insulin, behavior, learning, memory, and transcription factor (Figure $2 \mathrm{~A}-\mathrm{C}$ and Extended data, Workbook 4, sheets 1-6 $\left.{ }^{21}\right)$. Each of the correlates for the genesets are evaluated for keywords related to the phenotypes of narcolepsy, PD, and IR in the hypothalamus, dorsal thalamus, pons, and subcoeruleus nucleus. Most of the keywords of the three sets of gene correlates are associated with subcoeruleus nucleus.

The LRRK2 gene correlates have the highest frequency of the keyword categories. The highest represented categories are: transcription factor (hypothalamus), insulin, behavior, learning, memory, locomotion (dorsal thalamus), dopamine, Parkinson, and sleep (subcoeruleus nucleus) and circadian processes (equal frequency in dorsal thalamus and subcoeruleus nucleus).

The highest represented keyword categories for $H L A-D Q B 1$ are behavior, insulin, transcription factor, circadian, memory, dopamine, sleep (subcoeruleus nucleus), locomotion (hypothalamus), and learning (equal frequencies in the hypothalamus and subcoeruleus nucleus). The highest represented categories of HCRT are transcription factor, behavior, insulin, circadian, dopamine, Parkinson, memory, sleep, locomotion (subcoeruleus nucleus), and learning (hypothalamus).

\section{Functional analysis of PD, narcolepsy, and IR risk factor} and related genes

PD, narcolepsy, and IR risk factor and related genesets were evaluated to identify a common set of genes associated with the three disorders (Extended data, Workbook 5, sheets 1-4 ${ }^{18}$ ). There were 38 shared genes between the PD and narcolepsy genesets. CAMKID is the only gene common among the three genesets for PD, narcolepsy, and IR and it is a Calcium/ Calmodulin kinase that is upregulated in PD patients and is also a risk factor for Type 2 diabetes ${ }^{22,23}$.

Of the common PD and narcolepsy genes, several were directly associated with PD and narcolepsy behavioral phenotypes such as locomotion (DRD2, DRD3, DRD4, GDNF, SLC18A2), sleep (HTR2A, DRD2, DRD3, GRIN2A, NLGN1), circadian processes (PPARGC1A, CACNA1C, DRD2, DRD3, DRD4, GRIN2, $M A P K 1, N L G N 1)$, circadian entrainment (CACNA1C, GRIN2A, MAPK1), learning (COMT, DRD1,DRD2, DRD3 GRIN2A) and memory (GRIN2A, HTR2A, COMT, DRD1, DRD2, DRD3). There were two common genes between the PD and IR genesets: $R R E B 1$, which is a transcription factor, and $A N K F Y 1$, which is involved in vesicle trafficking and is also implicated in Type 2 diabetes. There is one common gene between narcolepsy and IR: $H L A-D Q B 1$, which is the narcolepsy associated gene under study here.

The enrichment results are visualized as a network of functionally grouped terms and pathways and listed in the accompanying bar graph (Figure 3A, B, Extended data, Workbook 5, sheet $5^{18}$ ). The most significant term of a given group is highlighted as the leading term in the network which is indicated by color. The most significant terms emphasized in the graph 
A

LRRK2

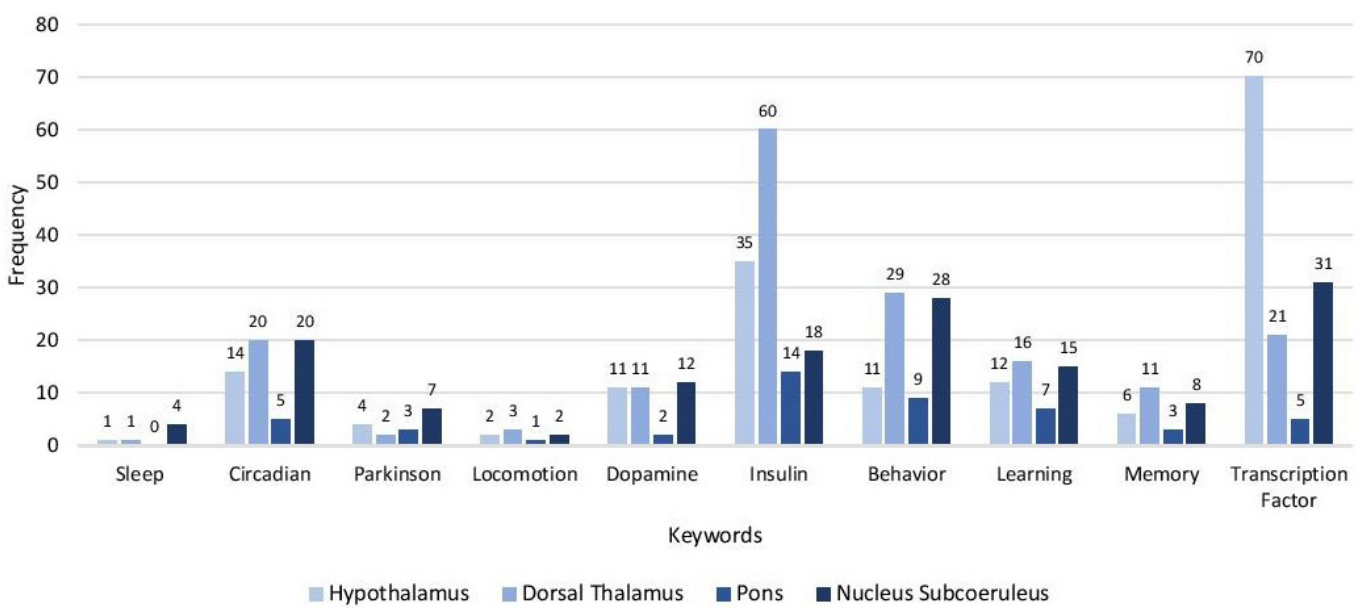

B

HLA-DQB1
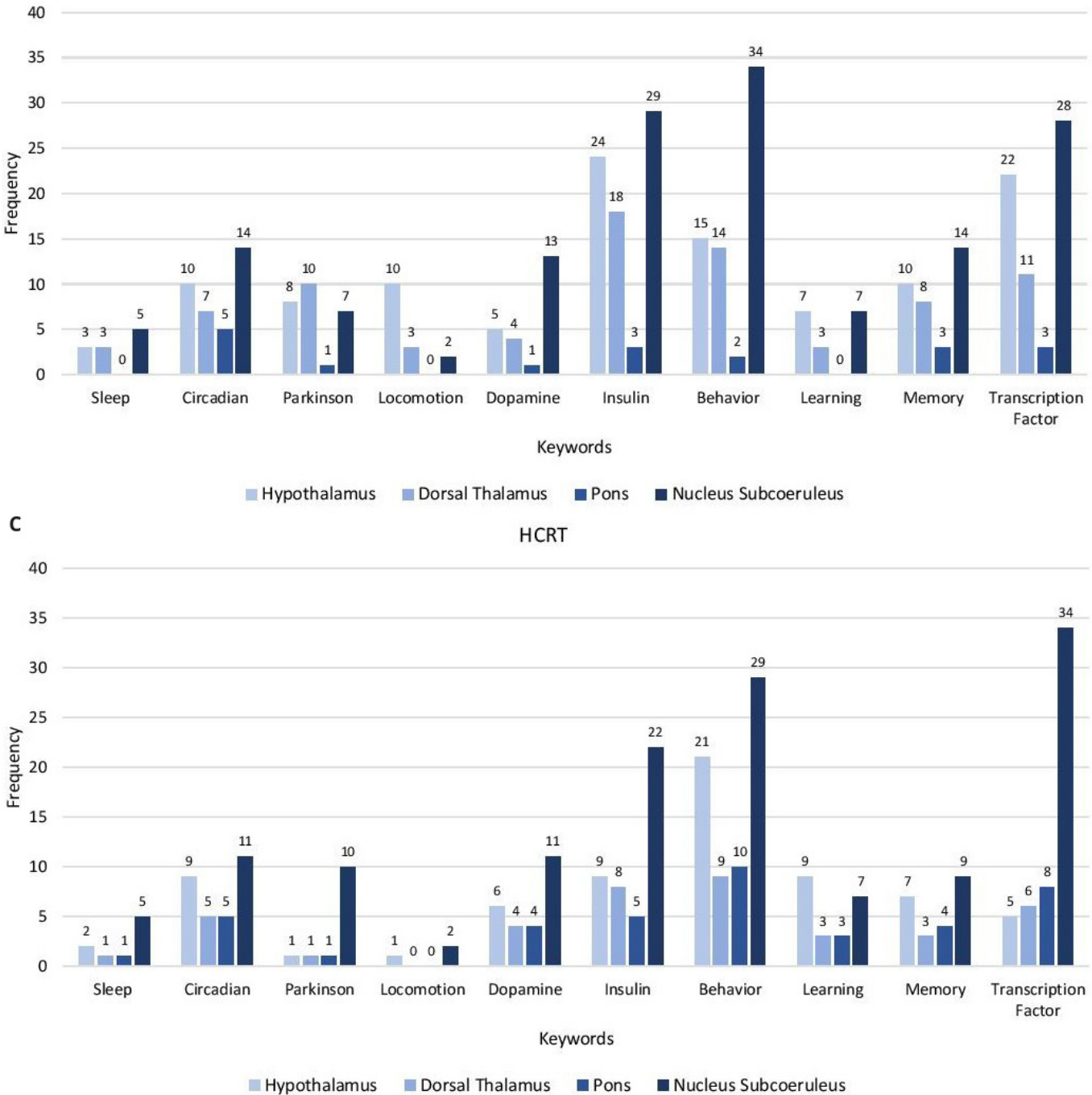

Figure 2. Keyword enrichment. Representative keyword enrichment of the gene correlates of LRRK2, HLA-DQB1 and HCRT in the Hypothalamus, Dorsal Thalamus, Pons and Nucleus Subcoeruleus based on GO term classification. (A) LRRK2 gene correlates (B) HLA-DQB1 gene correlates (C) HCRT gene correlates. X-axis, keyword categories; Y-axis, frequency of occurrence. 


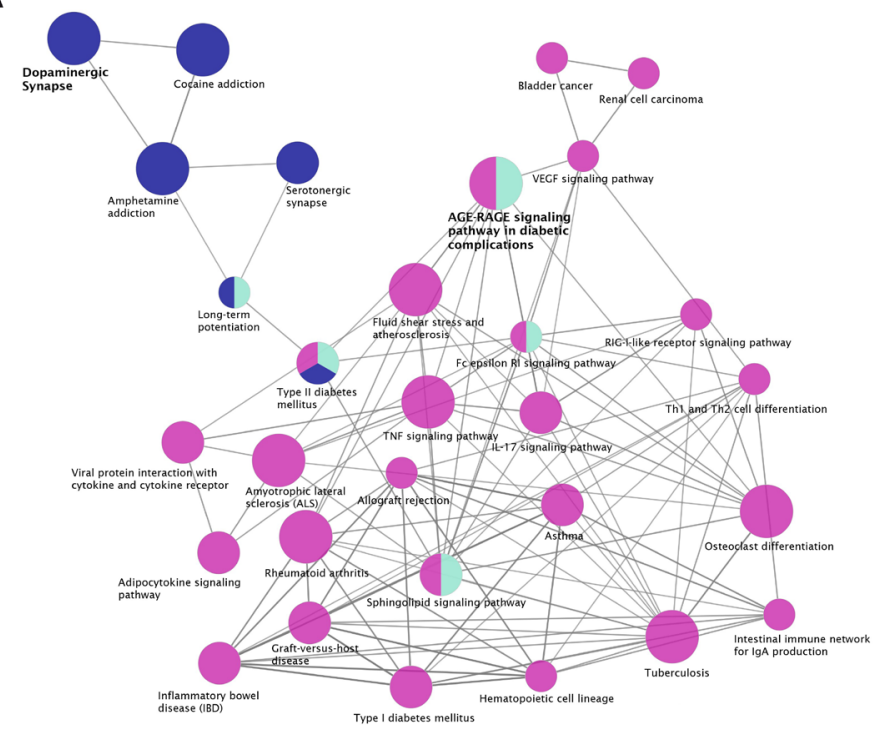

B

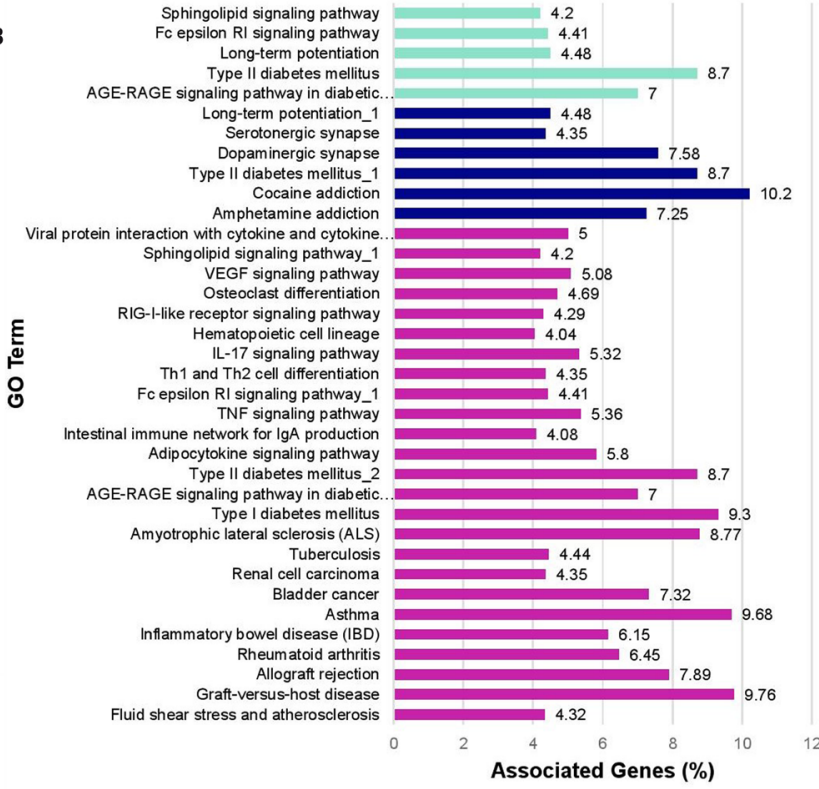

Figure 3. Enrichment network analysis. (A) Risk factors enrichment network. In the network the color gradient indicates the proportion of genes in each cluster associated with the enriched GO term. Dark blue nodes include dopaminergic synapse and pathways related to the reward system. Cyan nodes include the AGE-RAGE Signaling pathway in diabetic complications, immune system pathways and lipid signaling. Magenta nodes involve terms associated with immune system function and also insulin signaling. (B) GO pathway terms and associated genes. Bar graph showing the percentage of genes connected with the GO terms. Bars are colored according to the network (Figure 3A).

are dopaminergic synapse (ten genes, KEGG ID:04728, $\mathrm{P}=2.77 \mathrm{E}-09)$ and the AGE-RAGE signaling pathway in diabetic complications (seven genes, KEGG ID:04933, P=4.70E-06) both of which are relevant to PD and IR. Other relevant enriched GO Terms include Type I diabetes mellitus (four genes, KEGG:04940, P=6.27E-04), Type II diabetes mellitus (four genes, KEGG:04930, P=7.54E-04), and Amyotrophic lateral sclerosis (five genes, KEGG:05014, P=9.56E-05). The other enriched terms in the network also represent pathways linked to the reward system, serotonin signaling, immune system function, and insulin regulation. There are several points of convergence in the graph where the enriched terms overlap: AGE-RAGE, Sphingolipid, and Fc Epsilon RI signaling pathways as well as long term potentiation (Extended data, Workbook 5, sheet $5^{18}$ ).

\section{The PD, narcolepsy, and IR connection}

A protein-protein interaction network revealed the insulin connection between the $L R R K 2$ and $H L A-D Q B 1$ networks using the multiple protein option in the STRING database (Figure 4A, Extended data, Workbook 6, sheets 1-2 ${ }^{24}$ ). The distribution for the PPI scores for each show that the majority of the interactions fall in the high range with scores between 0.7 and 1.0 (Figure 4B). Insulin (INS) and its receptor (INSR) are connected to $H L A-D B Q 1$ through $1 \mathrm{st}$ shell interactions both of which are based on crystallographic evidence. INSR is in turn connected to CALM1, a calmodulin binding protein involved in calcium signaling and associated with diverse processes including circadian entrainment (KEGG pathway 04713). The evidence for the INSR/CALMI interaction is based on coimmunoprecipitation, electro mobility shift, and western blot assays. Relevant interactions, scores, and references are provided in Table 1.

In the network, CALMI bridges INSR, CAMKID (the only common gene among the database curated genesets for PD, narcolepsy, and IR), and LRRK2. The CALM1 and CAMK1D relationship is supported by coimmunoprecipitation and filter binding and phage display assays. The CALM1/LRRK2 interaction is supported by cosedimentation, coimmunoprecipitation and genetic interference assays.

There are many proteins in the network related to insulin signaling (IDE, IGF1, IGF1R, INSRR, YWHAH, YWHAG, PRKCE, KCNN2, INS-IGF2, RAF1, CACNAIC, CALM1, CALM2, CALM3, $K C N N 2$, $P R K C E)$. Several genes are implicated in $\mathrm{AD}(C A C$ NAIC, CALM1, CALM2, CALM3, IDE), circadian entrainment (CACNA1C, CALM1, CALM2, CALM3), and dopamine signaling (CACNAIC, CALM1, CALM2, CALM3, LRRK2). LRRK2 is the only gene in the network linked to PD. There were no experimentally validated interacting partners for $H C R T$ and it did not connect to the network.

\section{Discussion}

The aim of this study is to identify the underlying genes and pathways linking PD, narcolepsy, and IR. An integrative genomics and systems biology approach was used for the analysis of gene expression patterns of the LRRK2, HLA-DQB1, and $H C R T$ 
A

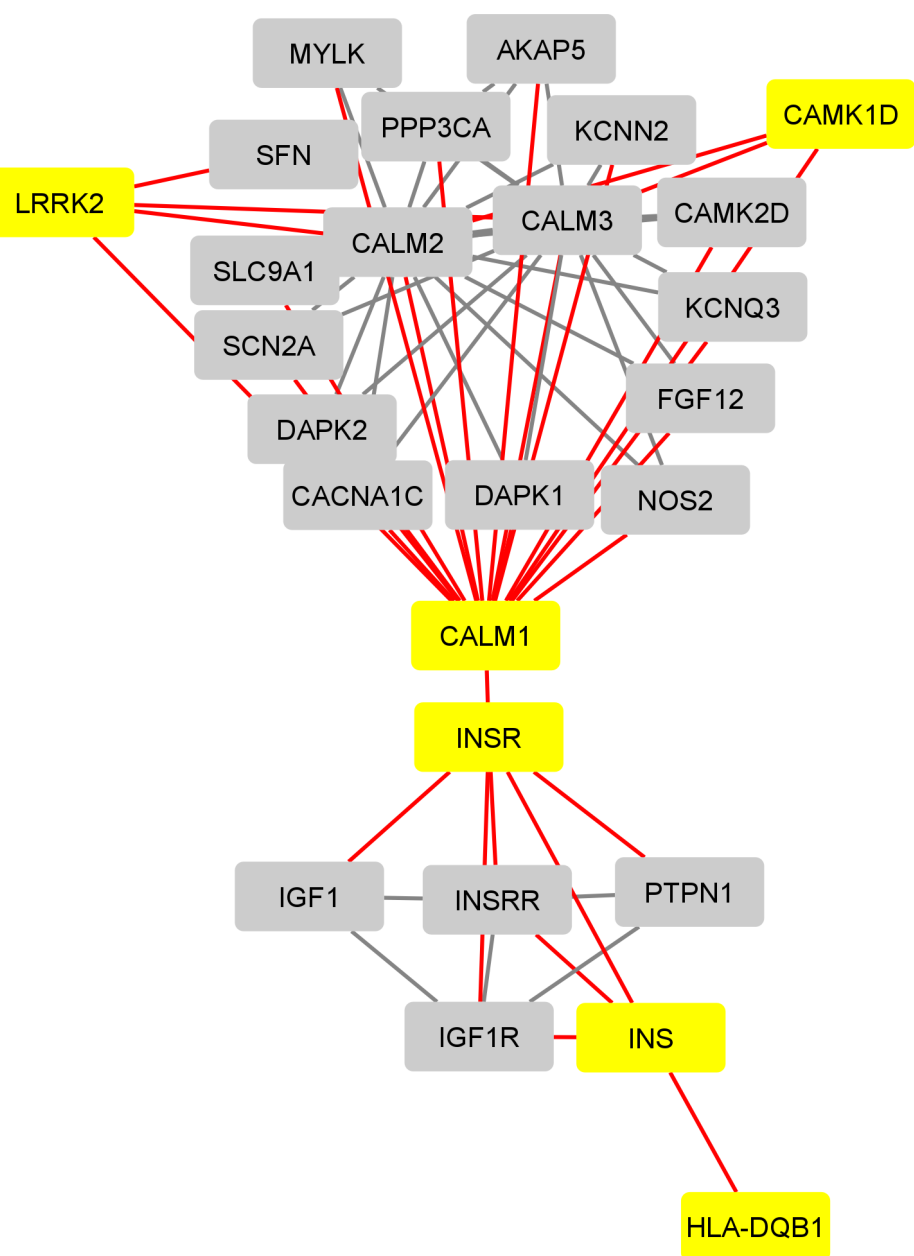

B

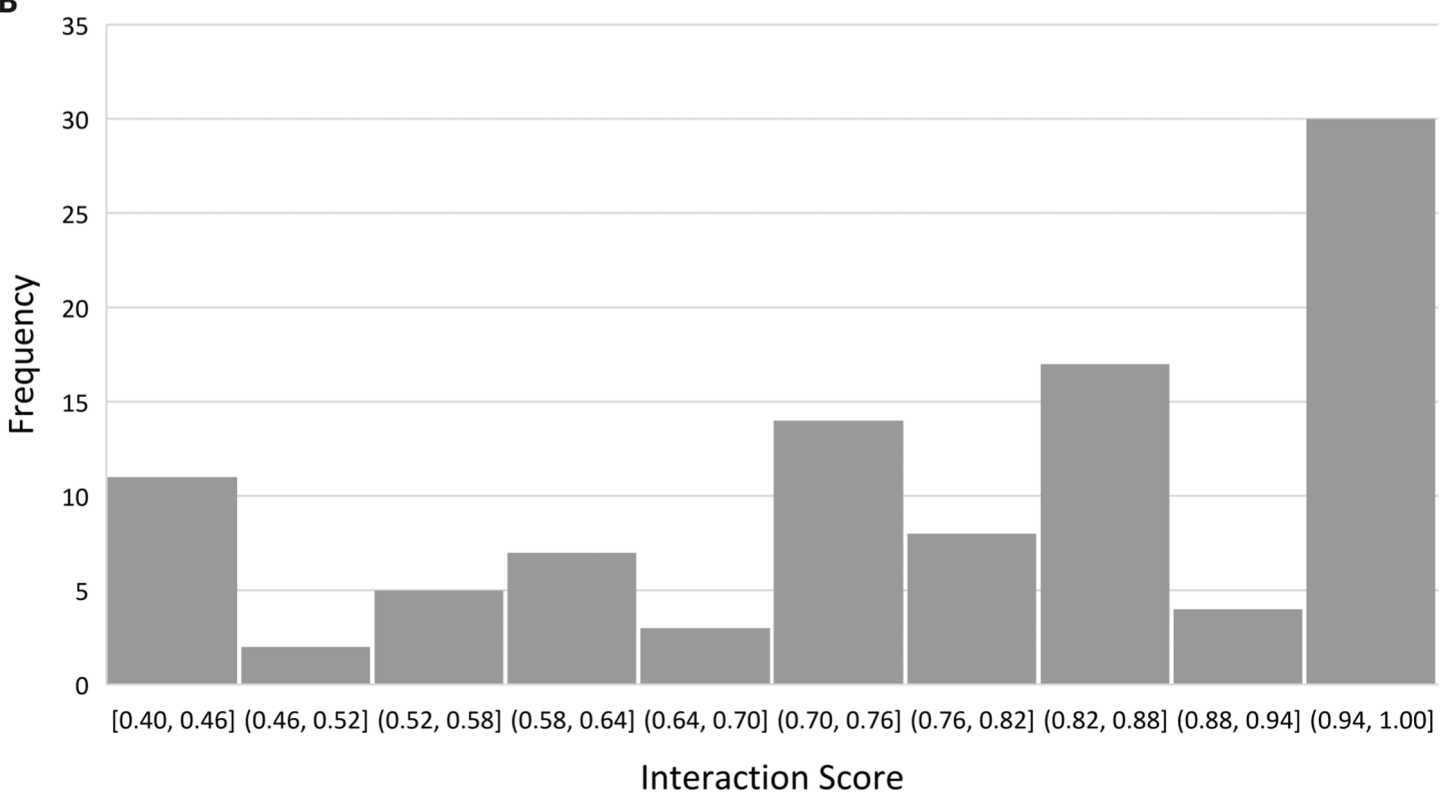

Figure 4. PPI network linking narcolepsy and Parkinson's through insulin. (A) PPI network showing the insulin interaction with the Narcolepsy gene (HLA-DQB1) and Parkinson's disease gene (LRRK2.) (B) Interaction score distribution, X-axis, interaction score; Y-axis, frequency. 
Table 1. LRRK2, HLA-DQB1 and CAMK1D relevant network interactions and scores.

\begin{tabular}{|l|c|c|}
\hline \multicolumn{1}{|c|}{ PPI } & Score & References \\
\hline INS-INSR & 0.974 & 25 \\
\hline CALM1-CAMK1D & 0.732 & 26 \\
\hline INS-HLA-DQB1 & 0.72 & 27 \\
\hline CALM1-INSR & 0.433 & 28 \\
\hline CALM1-LRRK2 & 0.403 & 29 \\
\hline
\end{tabular}

genes which are strongly associated with each of these disorders. A comparison of the shared gene correlates for sleep, neurodegeneration, behavior, and insulin led to the identification of genes such as CACNAIC, BHLHE41, HMGB1, and CAMK1D whose defects might be plausible for the narcoleptic-like symptoms in PD and the relationship with IR.

In addition to the PD- and insulin-related enrichment terms for the $H L A-D Q B 1$ correlates resulting from the cluster analysis, a large number of highly significant genes and terms associated with olfactory processes and keratinocytes/keratin were obtained. The olfaction related genes identified here may be relevant to PD because $\mathrm{PD}$ involves degeneration of the olfactory system, which often begins with an impaired sense of smell $^{30}$. Moreover, diabetes has also been linked to olfactory dysfunction ${ }^{31}$. There is also evidence supporting a link between PD and keratinocytes and keratin. In a study that considered the effects of PD on non-neuronal tissues, it was reported that individuals with PD had a higher incidence of melanoma and non-melanoma skin cancers ${ }^{32}$. Interestingly, a link with diabetes and keratinocytes and keratin is most evident in the slow rate of wound healing attributed to high blood glucose levels ${ }^{33}$.

The PPI network of $L R R K 2, H L A-D Q B 1$, and $C A M K 1 D$ reveals a connection with several insulin/diabetes, circadian, and PD risk factor genes supporting our hypothesis that these three disorders have common pathogenetic processes, further supporting other studies that have reported a relationship between them. Moreover, gene variants of narcolepsy-related genes, $H L A-D Q B 1$ and $C A M K 1 D$, are associated with diabetes, IR, and PD.

The RAGE signaling pathway, identified here through GO enrichment of the shared genesets, may be central to connecting $\mathrm{PD}$ and IR. RAGE is associated with the pathogenesis of several disorders, including diabetes, via inflammation. RAGE is also highly expressed in PD patients when compared with age-matched controls. RAGE gene variants have been linked to sporadic PD in an Asian population ${ }^{34,35}$, indicating that $R A G E$ might play a role in the pathogenesis of PD. Moreover, silencing of the RAGE pathway in a mouse model of PD improved neuroinflammation which causes dopaminergic neurodegeneration in PD patients ${ }^{36}$. This is important because the deterioration of dopaminergic neurons in the brain is believed to play a critical role in the development of $\mathrm{PD}^{37}$. By the time clinical signs of $\mathrm{PD}$ are identified and a diagnosis is made, a large number of dopaminergic neurons are already lost ${ }^{1}$. Dopaminergic neurons are also involved in promoting feeding behavior in the hypoglycemic state which is mediated by insulin receptors in the substantia nigra, indicating that dopaminergic neuronal loss may alter glycemic control ${ }^{38,39}$. Loss of orexin/hypocretin is also linked to binge-eating behavior, low BMR, and obesity, which is also a symptom of narcolepsy. In addition, type 2 diabetes is strongly associated with an increased risk of PD.

Additional insight into the relationship between these disorders is evident from studies in which the repurposing of treatment for one of these diseases has been used to alleviate symptoms in another. Results from a recent clinical trial in which PD patients were treated with intranasal insulin, reported that test subjects had improved verbal fluency and motor skills and sleep related symptoms ${ }^{40}$. Melatonin, the naturally occurring hormone that controls sleep and wake cycles, was also found to be beneficial in $\mathrm{PD}^{41}$.

There are more than 10 million people worldwide that live with Parkinson's disease. Additional studies aimed at identifying genes and regulatory factors underlying and bridging these comorbid disorders may aid in the design of early intervention and diagnosis strategies, as well as treatment regimes for patients with $\mathrm{PD}$, diabetes, and/or narcolepsy.

\section{Conclusion}

We have identified the genetic signatures that link PD with its comorbid disorders, narcolepsy and insulin resistance, from the convergence and intersection of dopaminergic, insulin, and immune system related signaling pathways. These findings may aid in the design of early intervention strategies and treatment regimes for non-motor symptoms in PD patients as well as individuals with diabetes and narcolepsy.

\section{Data availability}

Underlying data

All data underlying the results are available as part of the article and no additional source data are required.

\section{Extended data}

Figshare: Extended data workbook 1 LRRK2, HLA-DQB1, and HCRT gene correlates.xlsx. https://doi.org/10.6084/ m9.figshare.13072037.v1 ${ }^{17}$.

This file contains gene correlates of LRRK2, HLA-DQB1 and HCRT in the hypothalamus, dorsal thalamus, pons and nucleus subcoeruleus.

Figshare: Extended data workbook 2 Cluster analysis of gene correlates.xlsx. https://doi.org/10.6084/m9.figshare.13072103.v1 ${ }^{19}$.

This file contains cluster analysis of gene correlates of LRRK2, HLA-DQB1 and HCRT in the hypothalamus, dorsal thalamus, pons and nucleus subcoeruleus.

Figshare: Extended data workbook 3 Common genes and functions. xlsx. https://doi.org/10.6084/m9.figshare.13072124.v120. 
This file contains gene set overlap and functional analysis for LRRK2, HLA-DQB1, and HCRT gene correlates.

Figshare: Extended data workbook 4 Keyword genes.xlsx. https:// doi.org/10.6084/m9.figshare.13072130.v121.

This file contains keyword enrichment of gene correlates of LRRK2, HLA-DQB1 and HCRT.

Figshare: Extended data workbook 5 PD, narcolepsy and IR risk factors genes.xlsx. https://doi.org/10.6084/m9.figshare. 13072151.v1 $1^{18}$.

This file contains Parkinson's disease, narcolepsy and Insulin resistance risk factors genes
Figshare: Extended data workbook 6 LRRK2, HLA-DQB1 and CAMK1D protein-protein interaction network.xlsx. https://doi. org/10.6084/m9.figshare.13072160.v124.

This file contains LRRK2, HLA-DQB1 and CAMK1D proteinprotein interaction network coordinates.

Extended data are available under the terms of the Creative Commons Attribution 4.0 International license (CC-BY 4.0).

Author contributions

$\mathrm{AC}$ and $\mathrm{AD}$ designed the project, $\mathrm{AC}, \mathrm{AD}$, and WEC did the formal analysis, writing and editing of the manuscript. All authors approved the final version of the manuscript.
1. Lew M: Overview of Parkinson's disease. Pharmacotherapy. 2007; 27(12 Pt 2): 155S-160S.

PubMed Abstract | Publisher Full Text

2. Non-dopamine Lesions in Parkinson's Disease. Oxford Medicine n.d. accessed September 8, 2020).

Reference Source

3. Li JQ, Tan L, YU JT: The role of the LRRK2 gene in Parkinsonism. Mol Neurodegener. 2014; 9: 47.

PubMed Abstract | Publisher Full Text | Free Full Text

4. Ylikoski A, Martikainen K, Sarkanen T, et al.: Parkinson's disease and narcolepsy-like symptoms. Sleep Med. 2015; 16(4): 540-4. PubMed Abstract | Publisher Full Text

5. Haq IZ, Naidu Y, Reddy $P$, et al.: Narcolepsy in Parkinson's disease. Expert Rev Neurother. 2010; 10(6): 879-84.

PubMed Abstract | Publisher Full Text

6. Krcmarova M, Dusek P, Kovalska P, et al:: Narcolepsy with cataplexy and parkinson's disease - A case report. Sleep Med. 2013; 14(1): e174-5. Publisher Full Text

7. Guilleminault C: narcolepsy. Sleep Disorders Medicine. Elsevier. 1994; 241-54. Publisher Full Text

8. Miyagawa T, Tokunaga K: Genetics of narcolepsy. Hum Genome Var. 2019; 6: 4 PubMed Abstract | Publisher Full Text | Free Full Text

9. Wissemann WT, Hill-Burns EM, Zabetian CP, et al.: Association of Parkinson disease with structural and regulatory variants in the $H L A$ region. Am J Hum Genet. 2013; 93(5): 984-93.

PubMed Abstract | Publisher Full Text | Free Full Text

10. Mignot E: Genetic and familial aspects of narcolepsy. Neurology. 1998; 50(2 Suppl 1): S16-22.

PubMed Abstract | Publisher Full Text

11. Hu G, Jousilahti P, Bidel S, et al.: Type 2 diabetes and the risk of Parkinson's disease. Diabetes Care. 2007; 30(4): 842-7.

PubMed Abstract | Publisher Full Text

12. Sandyk R: The relationship between diabetes mellitus and Parkinson's disease. Int J Neurosci. 1993; 69(1-4): 125-30. PubMed Abstract | Publisher Full Text

13. Ebrahim IO, Howard RS, Kopelman MD, et al.: The hypocretin/orexin system. I $R$ Soc Med. 2002; 95(5): 227-30.

PubMed Abstract | Publisher Full Text | Free Full Text

14. Bourgin $P$, Huitrón-Résendiz S, Spier AD, et al.: Hypocretin-1 modulates rapid eye movement sleep through activation of locus coeruleus neurons. Neurosci. 2000; 20(20): 7760-5

PubMed Abstract | Publisher Full Text | Free Full Text

15. Thannickal TC, Lai YY, Siegel JM: Hypocretin (orexin) cell loss in Parkinson's disease. Brain. 2007; 130(Pt 6): 1586-95. PubMed Abstract | Publisher Full Tex

16. Loss of hypocretin neurons might cause sleep disturbance in PD. Nat Rev Neurol. 2007; 3: 421-421.

Publisher Full Text

17. Delprato A: Extended data workbook 1 LRRK2, HLA-DQB1, and HCRT gene correlates.xlsx. figshare. Dataset. 2020.

http://www.doi.org/10.6084/m9.figshare.13072037.v1
18. Delprato A: Extended data workbook 5 PD, narcolepsy and IR risk factors genes.xIsx. figshare. Dataset. 2020.

http://www.doi.org/10.6084/m9.figshare.13072151.v1

19. Delprato A: Extended data workbook 2 Cluster analysis of gene correlates. xlsx. figshare. Dataset. 2020.

http://www.doi.org/10.6084/m9.figshare.13072103.v1

20. Delprato A: Extended data workbook 3 Common genes and functions.xIsx figshare. Dataset. 2020

http://www.doi.org/10.6084/m9.figshare.13072124.v1

21. Delprato A: Extended data workbook 4 Keyword genes.xlsx. figshare. Dataset. 2020.

http://www.doi.org/10.6084/m9.figshare.13072130.v1

22. Xue A, Wu Y, Zhu Z, et al.: Genome-wide association analyses identify 143 risk variants and putative regulatory mechanisms for type $\mathbf{2}$ diabetes. Nat Commun. 2018; 9(1): 2941.

PubMed Abstract | Publisher Full Text | Free Full Text

23. Jin $\mathrm{X}, \mathrm{Li}$, Li W, et al.: Weighted gene co-expression network analysis reveals specific modules and biomarkers in Parkinson's disease. Neurosci Lett. 2020; 728: 134950.

PubMed Abstract | Publisher Full Text

24. Delprato A: Extended data workbook 6 LRRK2, HLA-DQB1 and CAMK1D protein-protein interaction network.xlsx. figshare. Dataset. 2020. http://www.doi.org/10.6084/m9.figshare.13072160.v1

25. Menting JG, Whittaker J, Margetts MB, et al.: How insulin engages its primary binding site on the insulin receptor. Nature. 2013; 493(7431): 241-5. PubMed Abstract | Publisher Full Text | Free Full Text

26. Pausch $\mathrm{MH}$, Kaim D, Kunisawa R, et al:: Multiple Ca2+/calmodulin-dependent protein kinase genes in a unicellular eukaryote. EMBO J. 1991; 10(6): 1511-22.

PubMed Abstract | Free Full Text

27. Lee KH, Wucherpfennig KW, Wiley DC: Structure of a human insulin peptideHLA-DQ8 complex and susceptibility to type 1 diabetes. Nat Immunol. 2001; 2(6): $501-7$

PubMed Abstract | Publisher Full Text

28. Kim HS, Jung MS, Lee $\mathrm{K}$, et al.: An S-locus receptor-like kinase in plasma membrane interacts with calmodulin in Arabidopsis. FEBS Lett. 2009; 583(1): $36-42$.

PubMed Abstract | Publisher Full Text

29. Meixner A, Boldt K, Van Troys M, et al.: A QUICK screen for Lrrk2 interaction partners--leucine-rich repeat kinase $\mathbf{2}$ is involved in actin cytoskeleton dynamics. Mol Cell Proteomics. 2011; 10(1): M110.001172. PubMed Abstract | Publisher Full Text | Free Full Text

30. Doty RL, Hawkes CH, Berendse HW: Olfactory dysfunction in Parkinson's disease and related disorders. In: Halliday, PhD G, Barker, MRCP, PhD R, Rowe, FRACP, PhD D, editors. Non-dopamine Lesions in Parkinson's Disease. Oxford University Press; 2010; 65-91.

31. Zaghloul H, Pallayova M, Al-Nuaimi O, et al.: Association between diabetes mellitus and olfactory dysfunction: current perspectives and future directions. Diabet Med. 2018; 35(1): 41-52. PubMed Abstract | Publisher Full Text

32. Planken $A$, Kurvits $L$, Reimann $E$, et al.: Looking beyond the brain to improve the pathogenic understanding of Parkinson's disease: implications of 
whole transcriptome profiling of Patients' skin. BMC Neurol. 2017; 17(1): 6. PubMed Abstract | Publisher Full Text | Free Full Text

33. Spravchikov N, Sizyakov G, Gartsbein M, et al.: Glucose effects on skin keratinocytes: implications for diabetes skin complications. Diabetes. 2001 50(7): 1627-35.

PubMed Abstract | Publisher Full Text

34. Guerrero E, Vasudevaraju P, Hegde ML, et al.: Recent advances in $\boldsymbol{\alpha}$-synuclein functions, advanced glycation, and toxicity: implications for Parkinson's disease. Mol Neurobiol. 2013; 47(2): 525-36. PubMed Abstract | Publisher Full Text

35. Gao J, Teng J, Liu H, et al.: Association of RAGE gene polymorphisms with sporadic Parkinson's disease in Chinese Han population. Neurosci Lett. 2014 559: $158-62$.

PubMed Abstract | Publisher Full Text

36. Wang $X$, Sun $X$, Niu M, et al.: RAGE Silencing Ameliorates Neuroinflammation by Inhibition of p38-NF-k B Signaling Pathway in Mouse Model of Parkinson's Disease. Front Neurosci. 2020; 14: 353.

PubMed Abstract | Publisher Full Text | Free Full Text
37. Mamelak M: Parkinson's disease, the dopaminergic neuron and gammahydroxybutyrate. Neurol Ther. 2018; 7(1): 5-11. PubMed Abstract | Publisher Full Text | Free Full Text

38. Sergi D, Renaud J, Simola N, et al.: Diabetes, a contemporary risk for Parkinson's disease: epidemiological and cellular evidences. Front Aging Neurosci. 2019; 11: 302.

PubMed Abstract | Publisher Full Text | Free Full Text

39. Fiory F, Perruolo G, Cimmino I, et al.: The relevance of insulin action in the dopaminergic system. Front Neurosci. 2019; 13: 868 PubMed Abstract | Publisher Full Text | Free Full Text

40. Intranasal Insulin May Ease Parkinson's Cognitive and Motor Symptoms, Early Study Shows n.d. (accessed September 7, 2020). Reference Source

41. Pandi-Perumal SR, BaHammam AS, Brown GM, et al:: Melatonin antioxidative defense: therapeutical implications for aging and neurodegenerative processes. Neurotox Res. 2013; 23(3): 267-300.

PubMed Abstract | Publisher Full Text 


\section{Open Peer Review}

\section{Current Peer Review Status: ? ? ?}

\section{Version 1}

Reviewer Report 06 May 2021

https://doi.org/10.5256/f1000research.30294.r83029

(C) 2021 Enterría-Morales D. This is an open access peer review report distributed under the terms of the Creative Commons Attribution License, which permits unrestricted use, distribution, and reproduction in any medium, provided the original work is properly cited.

\section{Daniel Enterría-Morales}

Neurobiology Section, Division of Biological Sciences, University of California San Diego, La Jolla, CA, USA

Parkinson's disease is the second most common neurodegenerative disease right after Alzheimer's disease nowadays. There is no treatment to counteract the symptoms of the disease, and most of the medications used are aimed at alleviating the symptoms. However, the use of these drugs also has disadvantages in the form of side effects, which makes the quality of life of the patients drop drastically. Lately, research on Parkinson's disease has been focused on the detection of markers that allow diagnosis of this disorder in early stages to increase the probabilities of treatments being effective. Within these types of studies, we have this article published by Chunduri et al., in which the main objective is the search for the expression of certain genes shared between Parkinson's disease, insulin resistance and narcolepsy. The authors propose to analyze the molecular bases of the comorbidity of these three disorders in order to find risk factors that could predispose and facilitate the early diagnosis of Parkinson's disease. As a result of the study, the authors have identified several genes that are related to the signaling pathways of dopamine, insulin and the immune system, among which are: CACNA1C, CAMK1D, BHLHE41, HMGB1, and the AGE-RAGE axis.

The preliminary data obtained in this study is interesting and would allow further research on the early diagnosis of this disorder, through the individualized study of each of these candidate genes, probably through knock-out or knock-down strategies in animal models. However, some parts of the article need to be supplemented with additional data, and furthermore, the discussion of the data obtained seems short and incomplete, so the authors should increase the number of bibliographic references that are currently discussing the analysis of comorbidity in Parkinson's disease, both in animal models and in humans.

Specifically, I would like the authors to address the following points:

1. It would be appropriate to validate the expression of some of these candidate genes in the mentioned brain regions, in the tissue of healthy human or wild-type animals (e.g. mouse, rat, monkey), mainly by quantitative PCR or in situ hybridization, or alternatively by Western 
Blot or immunohistochemistry. It would be very interesting if the authors could also analyze the expression of these genes in tissue from patients or animal models of Parkinson's disease.

2. It would be quite useful to validate the data obtained in humans, with the gene expression database available for mouse or monkey brain tissue, on the Allen Brain Institute website. Mouse Brain Atlas: https://developingmouse.brain-map.org/search/index Non-human primate Brain Atlas: https://www.blueprintnhpatlas.org/microarray/search

3. It would be great if the authors could comment on why they decided to analyze specifically the comorbidity of Parkinson's disease with insulin resistance and narcolepsy. There are other disorders that are more frequent comorbidities in Parkinson's disease patients, such as hypertension, Crohn's disease, schizophrenia, restless leg syndrome, anemia (see attached references). ${ }^{1,2,3}$

4. Could the authors comment and discuss if some of the candidate genes found are expressed in dopaminergic neurons in the human or mouse brain (regarding the bibliography available in the field)?

5. I suggest that the authors should cite more relevant references in the discussion section (see list of references attached). $4,5,6,7,8,9,10,11,12,13,14,15,16,17$

Once the authors are able to address all the issues I have proposed in this report, I would be willing to re-evaluate this manuscript.

\section{References}

1. Nalls MA, Saad M, Noyce AJ, Keller MF, et al.: Genetic comorbidities in Parkinson's disease.Hum Mol Genet. 2014; 23 (3): 831-41 PubMed Abstract | Publisher Full Text

2. Santos García D, Suárez Castro E, Expósito I, de Deus T, et al.: Comorbid conditions associated with Parkinson's disease: A longitudinal and comparative study with Alzheimer disease and control subjects.J Neurol Sci. 2017; 373: 210-215 PubMed Abstract | Publisher Full Text 3. Santiago JA, Bottero V, Potashkin JA: Biological and Clinical Implications of Comorbidities in Parkinson's Disease.Front Aging Neurosci. 2017; 9: 394 PubMed Abstract | Publisher Full Text 4. Wang L, Maldonado L, Beecham GW, Martin ER, et al.: DNA variants in CACNA1C modify Parkinson disease risk only when vitamin D level is deficient.Neurol Genet. 2016; 2 (3): e72 PubMed Abstract | Publisher Full Text

5. Wang X, Saegusa H, Huntula S, Tanabe T: Blockade of microglial Cav1.2 Ca2+ channel exacerbates the symptoms in a Parkinson's disease model. Scientific Reports. 2019; 9 (1). Publisher Full Text

6. Hurley MJ, Brandon B, Gentleman SM, Dexter DT: Parkinson's disease is associated with altered expression of CaV1 channels and calcium-binding proteins.Brain. 2013; 136 (Pt 7): 2077-97 PubMed Abstract | Publisher Full Text

7. Angelopoulou E, Piperi C, Papavassiliou AG: High-mobility group box 1 in Parkinson's disease: from pathogenesis to therapeutic approaches.J Neurochem. 146 (3): 211-218 PubMed Abstract I Publisher Full Text

8. Sasaki T, Liu K, Agari T, Yasuhara T, et al.: Anti-high mobility group box 1 antibody exerts neuroprotection in a rat model of Parkinson's disease.Exp Neurol. 2016; 275 Pt 1: 220-31 PubMed Abstract | Publisher Full Text 
9. Huang J, Yang J, Shen $Y$, Jiang $H$, et al.: HMGB1 Mediates Autophagy Dysfunction via Perturbing Beclin1-Vps34 Complex in Dopaminergic Cell Model.Front Mol Neurosci. 2017; 10: 13 PubMed Abstract | Publisher Full Text

10. Santoro $M$, Maetzler W, Stathakos $\mathrm{P}$, Martin $\mathrm{HL}$, et al.: In-vivo evidence that high mobility group box 1 exerts deleterious effects in the 1-methyl-4-phenyl-1,2,3,6-tetrahydropyridine model and Parkinson's disease which can be attenuated by glycyrrhizin.Neurobiol Dis. 91: 59-68 PubMed Abstract | Publisher Full Text

11. Gao HM, Zhou H, Zhang F, Wilson BC, et al.: HMGB1 acts on microglia Mac1 to mediate chronic neuroinflammation that drives progressive neurodegeneration.J Neurosci. 2011; 31 (3): 1081-92 PubMed Abstract | Publisher Full Text

12. Derk J, MacLean M, Juranek J, Schmidt AM: The Receptor for Advanced Glycation Endproducts (RAGE) and Mediation of Inflammatory Neurodegeneration.J Alzheimers Dis Parkinsonism. 2018; 8 (1). PubMed Abstract | Publisher Full Text

13. Jiang $X$, Wang $X$, Tuo $M$, Ma J, et al.: RAGE and its emerging role in the pathogenesis of Parkinson's disease. Neuroscience Letters. 2018; 672: 65-69 Publisher Full Text

14. Teismann $P$, Sathe $K$, Bierhaus $A$, Leng $L$, et al.: Receptor for advanced glycation endproducts (RAGE) deficiency protects against MPTP toxicity.Neurobiol Aging. 2012; 33 (10): 2478-90 PubMed Abstract | Publisher Full Text

15. Cho HJ, Xie C, Cai H: AGE-induced neuronal cell death is enhanced in G2019S LRRK2 mutation with increased RAGE expression.Transl Neurodegener. 2018; 7: 1 PubMed Abstract | Publisher Full Text

16. Salahuddin P, Rabbani G, Khan RH: The role of advanced glycation end products in various types of neurodegenerative disease: a therapeutic approach.Cell Mol Biol Lett. 2014; 19 (3): 407-37 PubMed Abstract | Publisher Full Text

17. Rungratanawanich W, Qu Y, Wang X, Essa MM, et al.: Advanced glycation end products (AGEs) and other adducts in aging-related diseases and alcohol-mediated tissue injury.Exp Mol Med. 2021; 53 (2): 168-188 PubMed Abstract | Publisher Full Text

Is the work clearly and accurately presented and does it cite the current literature? Partly

Is the study design appropriate and is the work technically sound? Partly

Are sufficient details of methods and analysis provided to allow replication by others? Yes

If applicable, is the statistical analysis and its interpretation appropriate? Yes

Are all the source data underlying the results available to ensure full reproducibility? Yes

Are the conclusions drawn adequately supported by the results? Partly

Competing Interests: No competing interests were disclosed. 
Reviewer Expertise: Neurodegeneration, Parkinson's disease, Neurochemistry.

\begin{abstract}
I confirm that I have read this submission and believe that I have an appropriate level of expertise to confirm that it is of an acceptable scientific standard, however I have significant reservations, as outlined above.
\end{abstract}

Author Response 29 Sep 2021

Anna Delprato, BioScience Project, Wakefield, USA

Reviewer 3

Parkinson's disease is the second most common neurodegenerative disease right after Alzheimer's disease nowadays. There is no treatment to counteract the symptoms of the disease, and most of the medications used are aimed at alleviating the symptoms. However, the use of these drugs also has disadvantages in the form of side effects, which makes the quality of life of the patients drop drastically. Lately, research on Parkinson's disease has been focused on the detection of markers that allow diagnosis of this disorder in early stages to increase the probabilities of treatments being effective. Within these types of studies, we have this article published by Chunduri et al., in which the main objective is the search for the expression of certain genes shared between Parkinson's disease, insulin resistance and narcolepsy. The authors propose to analyze the molecular bases of the comorbidity of these three disorders in order to find risk factors that could predispose and facilitate the early diagnosis of Parkinson's disease. As a result of the study, the authors have identified several genes that are related to the signaling pathways of dopamine, insulin and the immune system, among which are: CACNA1C, CAMK1D, BHLHE41, HMGB1, and the AGE-RAGE axis.

The preliminary data obtained in this study is interesting and would allow further research on the early diagnosis of this disorder, through the individualized study of each of these candidate genes, probably through knock-out or knock-down strategies in animal models. However, some parts of the article need to be supplemented with additional data, and furthermore, the discussion of the data obtained seems short and incomplete, so the authors should increase the number of bibliographic references that are currently discussing the analysis of comorbidity in Parkinson's disease, both in animal models and in humans.

Reviewer 3 comment:

Specifically, I would like the authors to address the following points:

It would be appropriate to validate the expression of some of these candidate genes in the mentioned brain regions, in the tissue of healthy human or wild-type animals (e.g. mouse, rat, monkey), mainly by quantitative PCR or in situ hybridization, or alternatively by Western Blot or immunohistochemistry. It would be very interesting if the authors could also analyze the expression of these genes in tissue from patients or animal models of Parkinson's disease.

Response: 
We have addressed the request for validation of candidate gene expression in the mentioned brain regions above in our response to Reviewer 1 and have added the information to the Results and Discussion sections of the revised manuscript. To summarize our findings, each of the key genes is expressed in at least two of the brain regions relevant to this study.

To address the reviewer's question concerning expression of these genes in tissue from patients or animal models of Parkinson's disease, we have analyzed the gene expression data available in the NCBI GEO database specifically for Parkinson's Disease datasets to determine if any of the key genes identified in our study are differentially expressed.

Out of 24 available datasets, we found that BHLHE41 and AGER were differentially expressed as compared with controls from two distinct studies (

https://www.ncbi.nlm.nih.gov/geo/geo2r/?acc=GSE36321 and https://wwww.ncbi.nlm.nih.gov/geo/query/acc.cgi?acc=GSE19587).

For BHLHE41, the study involved assessing gene expression in human neural stem cells containing the LRRK2 (G2019S) pathogenic mutation. The LRRK2 (G2019S) containing cells had higher expression of BHLHE4. AGER was differentially expressed with borderline significance in a study that examined post mortem medullary regions from brains with evidence of Parkinson's. AGER was expressed higher in brains from individuals with Parkinson's. However, due to low $n$ values we do not have enough confidence in the data to include these results in the manuscript. The other genes of interest, CACNA1C, CAMK1D, and HMGB1 were not identified in any of the GEO gene expression datasets as being expressed differently than controls.

We also assessed expression of the key genes in individuals with Parkinson's versus a healthy control group from data generated in a longitudinal study in which the aim is to identify biomarkers of Parkinson's disease progression (Parkinson's Progression Markers Initiative https://wwww.ppmi-info.org/). The Parkinson's cohort consisted of 423 individuals and the control group, 196. There was no difference in the expression for any of the key genes.

Reviewer 3 comment:

It would be quite useful to validate the data obtained in humans, with the gene expression database available for mouse or monkey brain tissue, on the Allen Brain Institute website. Mouse Brain Atlas: https://developingmouse.brain-map.org/search/index Non-human primate Brain Atlas: https://www.blueprintnhpatlas.org/microarray/search

\section{Response:}

Thank you for the suggestion. However, to the best of our knowledge, there is no Microarray data available for mouse at the Allen Brain Atlas but we were able to consider the in situ hybridization data (discussed above). Regrettably the Non-human primate atlas does not contain data for the relevant brain regions used in this study 
which is unfortunate because this is an intriguing dataset.

Reviewer 3 comment:

It would be great if the authors could comment on why they decided to analyze specifically the comorbidity of Parkinson's disease with insulin resistance and narcolepsy. There are other disorders that are more frequent comorbidities in Parkinson's disease patients, such as hypertension, Crohn's disease, schizophrenia, restless leg syndrome, anemia (see attached references).1,2,3

Response:

Initially, the focus of our study was to investigate the connection between Parkinson's and narcolepsy. Early on in the data collection and preliminary analysis, we observed that many of the gene correlates were linked to insulin resistance. On the basis of this finding we decided to expand the scope of the study.

Reviewer 3 comment:

Could the authors comment and discuss if some of the candidate genes found are expressed in dopaminergic neurons in the human or mouse brain (regarding the bibliography available in the field)?

Response:

AGER, BHLHE41, CACNA1C, and HMGB1 are expressed in Dopaminergic neurons from the substantia nigra pars compacta and ventral tegmental area in rats. These data are publicly accessible at GEO datasets, accession number: GSE1837 ( https://www.ncbi.nlm.nih.gov/geo/query/acc.cgi?acc=GSE1837).

There is also further support from previously published studies:

CACNA1C (PTSD study generated mice with specific deletion of cacna1c from D1Rexpressing neurons https://pubmed.ncbi.nlm.nih.gov/32332995/).

CAMK1D (Decreased mRNA Expression of Key ER Ca2+ Regulators and CamK1D in LRRK2 G2019S NeuronsD

https://www.sciencedirect.com/science/article/pii/S2213671118304909)

HMGB1/RAGE/AGER (Activation of the HMGB1-RAGE axis upregulates TH expression in dopaminergic neurons via JNK phosphorylation

https://pubmed.ncbi.nlm.nih.gov/28887039)

Reviewer 3 comment:

I suggest that the authors should cite more relevant references in the discussion section (see list of references attached).4,5,6,7,8,9,10,11,12,13,14,15,16,17 


\section{Response:}

We thank the reviewer for providing these references. We have updated the Introduction and Discussion sections of the revised manuscript to include this information.

Competing Interests: No competing interests were disclosed.

Reviewer Report 12 April 2021

https://doi.org/10.5256/f1000research.30294.r82398

(C) 2021 Wang Q. This is an open access peer review report distributed under the terms of the Creative Commons Attribution License, which permits unrestricted use, distribution, and reproduction in any medium, provided the original work is properly cited.

\section{Qing Wang}

Department of Neurology, Zhujiang Hospital, Southern Medical University, Guangzhou, Guangdong, China

This study has identified the genes such as CACNA1C, CAMK1D, BHLHE41, HMGB1, and AGE-RAGE that link PD with narcolepsy and insulin resistance and their signaling networks are connected through insulin and immune system pathways. These findings may contribute to develop new treatment strategies in PD patients as well as individuals with diabetes and narcolepsy. The results of the study are interesting.

However, the introduction and discussion are too weak. So it is suggested to cite more relevant references as follows (please see the reference list below) in order to elaborate on the mechanisms.

After my concerns above have been fully addressed, I am happy to re-evaluate this manuscript.

\section{References}

1. Ai H, Fang W, Hu H, Hu X, et al.: Antidiabetic Drug Metformin Ameliorates Depressive-Like Behavior in Mice with Chronic Restraint Stress via Activation of AMP-Activated Protein Kinase.Aging Dis. 2020; 11 (1): 31-43 PubMed Abstract | Publisher Full Text

2. Wang T, Yuan F, Chen Z, Zhu S, et al.: Vascular, inflammatory and metabolic risk factors in relation to dementia in Parkinson's disease patients with type 2 diabetes mellitus. Aging. 2020; 12

(15): 15682-15704 Publisher Full Text

3. Chu JS, Liu TH, Wang KL, Han CL, et al.: The Metabolic Activity of Caudate and Prefrontal Cortex Negatively Correlates with the Severity of Idiopathic Parkinson's Disease.Aging Dis. 2019; 10 (4): 847-853 PubMed Abstract | Publisher Full Text

4. Guo Y, Zhang C, Shang FF, Luo M, et al.: Ketogenic Diet Ameliorates Cardiac Dysfunction via Balancing Mitochondrial Dynamics and Inhibiting Apoptosis in Type 2 Diabetic Mice.Aging Dis. 2020; 11 (2): 229-240 PubMed Abstract | Publisher Full Text 
5. Zhu S, Deng B, Huang Z, Chang Z, et al.: "Hot cross bun" is a potential imaging marker for the severity of cerebellar ataxia in MSA-C.NPJ Parkinsons Dis. 2021; 7 (1): 15 PubMed Abstract | Publisher Full Text

6. Han R, Liu Z, Sun N, Liu S, et al.: BDNF Alleviates Neuroinflammation in the Hippocampus of Type 1 Diabetic Mice via Blocking the Aberrant HMGB1/RAGE/NF-kB Pathway.Aging Dis. 2019; 10 (3): 611-625 PubMed Abstract | Publisher Full Text

7. Wang L, Liu Y, Yan S, Du T, et al.: Disease Progression-Dependent Expression of CD200R1 and CX3CR1 in Mouse Models of Parkinson's Disease.Aging Dis. 2020; 11 (2): 254-268 PubMed Abstract I Publisher Full Text

8. Zhu S, Li H, Deng B, Zheng J, et al.: Various Diseases and Clinical Heterogeneity Are Associated With "Hot Cross Bun".Front Aging Neurosci. 2020; 12: 592212 PubMed Abstract | Publisher Full Text 9. Gao X, Huang Z, Feng C, Guan C, et al.: Multimodal analysis of gene expression from postmortem brains and blood identifies synaptic vesicle trafficking genes to be associated with Parkinson's disease. Briefings in Bioinformatics. 2020. Publisher Full Text

10. Han F, Li X, Yang J, Liu H, et al.: Salsalate Prevents $\beta$-Cell Dedifferentiation in OLETF Rats with Type 2 Diabetes through Notch1 Pathway.Aging Dis. 2019; 10 (4): 719-730 PubMed Abstract | Publisher Full Text

11. Zou J, Chen Z, Wei X, Chen Z, et al.: Cystatin C as a potential therapeutic mediator against Parkinson's disease via VEGF-induced angiogenesis and enhanced neuronal autophagy in neurovascular units. Cell Death \& Disease. 2017; 8 (6). Publisher Full Text

12. Gao L, Yu S, Cipriani A, Wu S, et al.: Neurological Manifestation of Incretin-Based Therapies in Patients with Type 2 Diabetes: A Systematic Review and Network Meta-Analysis.Aging Dis. 2019; 10 (6): 1311-1319 PubMed Abstract | Publisher Full Text

13. Zhang F, Niu L, Liu X, Liu Y, et al.: Rapid Eye Movement Sleep Behavior Disorder and Neurodegenerative Diseases: An Update.Aging Dis. 2020; 11 (2): 315-326 PubMed Abstract | Publisher Full Text

14. Ma WX, Tang J, Lei ZW, Li CY, et al.: Potential Biochemical Mechanisms of Brain Injury in Diabetes Mellitus.Aging Dis. 2020; 11 (4): 978-987 PubMed Abstract | Publisher Full Text 15. Yuan F, Guo X, Wei X, Xie F, et al.: Lee Silverman Voice Treatment for dysarthria in patients with Parkinson's disease: a systematic review and meta-analysis.Eur J Neurol. 27 (10): 1957-1970 PubMed Abstract | Publisher Full Text

16. Yang W, Chang Z, Que R, Weng G, et al.: Contra-Directional Expression of Plasma Superoxide Dismutase with Lipoprotein Cholesterol and High-Sensitivity C-reactive Protein as Important Markers of Parkinson's Disease Severity.Front Aging Neurosci. 2020; 12: 53 PubMed Abstract I Publisher Full Text

Is the work clearly and accurately presented and does it cite the current literature? Partly

Is the study design appropriate and is the work technically sound? Yes

Are sufficient details of methods and analysis provided to allow replication by others? Yes

If applicable, is the statistical analysis and its interpretation appropriate? Yes 
Are all the source data underlying the results available to ensure full reproducibility? Yes

Are the conclusions drawn adequately supported by the results? Yes

Competing Interests: No competing interests were disclosed.

I confirm that I have read this submission and believe that I have an appropriate level of expertise to confirm that it is of an acceptable scientific standard, however I have significant reservations, as outlined above.

Author Response 29 Sep 2021

Anna Delprato, BioScience Project, Wakefield, USA

Reviewer 2

This study has identified the genes such as CACNA1C, CAMK1D, BHLHE41, HMGB1, and AGERAGE that link PD with narcolepsy and insulin resistance and their signaling networks are connected through insulin and immune system pathways. These findings may contribute to developing new treatment strategies in PD patients as well as individuals with diabetes and narcolepsy. The results of the study are interesting.

Reviewer 2 comment:

However, the introduction and discussion are too weak. So it is suggested to cite more relevant references as follows (please see the reference list below) in order to elaborate on the mechanisms. After my concerns above have been fully addressed, I am happy to reevaluate this manuscript.

Response:

We thank the reviewer for providing us with many relevant references. Based on this information we have revised the Introduction and Discussion sections of the manuscript and have included more mechanistic detail and context as recommended.

Competing Interests: No competing interests were disclosed.

Reviewer Report 08 February 2021

https://doi.org/10.5256/f1000research.30294.r77250

(C) 2021 Hashimoto $\mathbf{M}$. This is an open access peer review report distributed under the terms of the Creative Commons Attribution License, which permits unrestricted use, distribution, and reproduction in any medium, provided the original work is properly cited.

\section{Makoto Hashimoto}


Laboratory for Parkinson's disease, Tokyo Metropolitan Institute of Medical Science, Tokyo, Japan

Comorbidity of Parkinson's disease (PD) with insulin resistance (IR) and narcolepsy-like sleep patterns are frequently described, but the mechanism is unclear.

In this study, an integrative genomics and systems biology approach was used to analyze gene expression patterns associated with PD, IR, and narcolepsy to identify genes and pathways that may shed light on how these disorders are interrelated. The results showed that the PD and narcolepsy signaling networks are connected through insulin and immune system pathways. Important genes and pathways that link PD, narcolepsy, and IR were shown to be CACNA1C, CAMK1D, BHLHE41, HMGB1, and AGE-RAGE. The authors concluded that these findings might aid in the design of early intervention strategies and treatment regimes for non-motor symptoms in PD patients as well as individuals with diabetes and narcolepsy.

Overall, the results are interesting and clear. I agree that the paper may contribute to the PD research. My comments are as follows:

1. It would be much better if modification of the expression of the identified genes (knockout or overexpression), including CACNA1C, CAMK1D, BHLHE41, HMGB1, and AGE-RAGE, might result in phenotypes related to PD and/or narcolepsy in cells or animal models. Are there such previous papers? Otherwise, the result of network analysis alone seems preliminary.

2. In the same context, other experiments, such as immunohistochemistry, should be conducted to confirm the expression of these genes at the protein level.

Is the work clearly and accurately presented and does it cite the current literature? Yes

Is the study design appropriate and is the work technically sound?

Yes

Are sufficient details of methods and analysis provided to allow replication by others? Yes

If applicable, is the statistical analysis and its interpretation appropriate? Yes

Are all the source data underlying the results available to ensure full reproducibility? Yes

Are the conclusions drawn adequately supported by the results? Partly

Competing Interests: No competing interests were disclosed.

Reviewer Expertise: neurodegenerative diseases

I confirm that I have read this submission and believe that I have an appropriate level of expertise to confirm that it is of an acceptable scientific standard, however I have significant reservations, as outlined above. 
Author Response 10 Mar 2021

Anna Delprato, BioScience Project, Wakefield, USA

We would like to thank you for taking the time to review our article and providing constructive feedback. We will submit a revised version once we have received all of the reviews.

Competing Interests: No competing interests were disclosed.

Author Response 29 Sep 2021

Anna Delprato, BioScience Project, Wakefield, USA

Reviewer 1

Comorbidity of Parkinson's disease (PD) with insulin resistance (IR) and narcolepsy-like sleep patterns are frequently described, but the mechanism is unclear.

In this study, an integrative genomics and systems biology approach was used to analyze gene expression patterns associated with PD, IR, and narcolepsy to identify genes and pathways that may shed light on how these disorders are interrelated. The results showed that the PD and narcolepsy signaling networks are connected through insulin and immune system pathways. Important genes and pathways that link PD, narcolepsy, and IR were shown to be CACNA1C, CAMK1D, BHLHE41, HMGB1, and AGE-RAGE. The authors concluded that these findings might aid in the design of early intervention strategies and treatment regimes for non-motor symptoms in PD patients as well as individuals with diabetes and narcolepsy.

Overall, the results are interesting and clear. I agree that the paper may contribute to the PD research. My comments are as follows:

Reviewer 1 comment:

It would be much better if modification of the expression of the identified genes (knockout or overexpression), including CACNA1C, CAMK1D, BHLHE41, HMGB1, and AGE-RAGE, might result in phenotypes related to PD and/or narcolepsy in cells or animal models.

Are there such previous papers? Otherwise, the result of network analysis alone seems Preliminary.

Response:

We thank the reviewer for taking the time to provide us constructive feedback on this manuscript. There is in fact a great deal of evidence derived from knockout and cell based studies linking CACNA1C, HMGB1, and AGER/AGE-RAGE to Parkinson's pathogenesis. CACNA1C is also associated with Circadian rhythm and narcolepsy. In addition, CAMK1D is a component of the calmodulin dependent calcium signaling cascade and there is also support for its role as an interactor of LRRK2, one of the key genes influencing Parkinson's. HMGB1 and AGER/AGE-RAGE appear to act in concert mediating inflammatory processes that ultimately lead to neuron cell death via NF-KB signaling. AGER/AGE-RAGE and LRRK2 are also linked as RAGE proteins are upregulated in LRRK2 G2019S mutant cells. The LRRK2 G2019S mutation is the most common genetic cause of neurodegeneration and PD. The other major gene of interest 
identified in the ppi network, BHLHE41, is a transcription factor associated with Circadian processes. Variants of BHLHE41 have been implicated in short sleep syndrome and this gene also has a role in immune function. BHLHE41 in addition to CAMK1D, RAGE, and HMGB1 are also implicated in diabetes.

Details of the supporting studies for the candidate genes as well as the other network genes have been included in the Introduction and Discussion sections of the revised manuscript.

Reviewer 1 comment:

In the same context, other experiments, such as immunohistochemistry, should be conducted to confirm the expression of these genes at the protein level.

Response:

We agree that the above mentioned studies could be useful to further support the results presented here. Regrettably we do not have access to wet lab facilities. Our method of research is based in bioinformatics, systems biology and integrative genomics.

However, we were able to address your question using legacy datasets from the Human Protein Atlas (https://wwww.proteinatlas.org/) which also contains data for gene expression in mice and pigs and the human database in the Allen Brain Atlas ( https://human.brain-map.org/microarray/search).

Results for gene expression of the key genes in the hypothalamus and pons are as follows: Each of the genes with the exception of AGER were expressed in both the hypothalamus and pons for human, mouse and pig. CACNA1C expression was also confirmed at the protein level by immunocytochemistry in the mouse hypothalamus and pons/medulla.

The expression pattern of the key genes in dorsal thalamus and subcoeruleus nucleus data were obtained for humans only and are as follows: HMGB1, AGER, BHLHE41 are expressed in both the dorsal thalamus and subcoeruleus nucleus. CACNA1C is expressed in the dorsal thalamus and is not expressed in the subcoeruleus nucleus CAMK1D was not expressed in either the dorsal thalamus or subcoeruleus nucleus. These data are have been added to the revised version of the manuscript.

Competing Interests: No competing interests were disclosed. 
The benefits of publishing with F1000Research:

- Your article is published within days, with no editorial bias

- You can publish traditional articles, null/negative results, case reports, data notes and more

- The peer review process is transparent and collaborative

- Your article is indexed in PubMed after passing peer review

- Dedicated customer support at every stage

For pre-submission enquiries, contact research@f1000.com 